\title{
DEPRESSION, ANXIETY AND STRESS AMONG GOVERNMENT NURSING COLLEGE STUDENTS IN AKOLA: A COLLEGE-BASED STUDY
}

\author{
Shilpa Telgote' Amol Jadhao $^{2}$
}

${ }^{1}$ Associate Professor, Department of Psychiatry, Government Medical College and Hospital, Akola. ${ }^{2}$ Assistant Professor, Department of Psychiatry, Government Medical College and Hospital, Akola.

ABSTRACT
BACKGROUND
Various studies done across the world found that the undergraduate students are at risk of developing psychological morbidity.
Prevalence of depression and anxiety was found to be higher in medical students compared to general population. In the
background of such studies in India among nursing students, the present study is envisaged.
The aim of the present study is to find out prevalence of Depression, Anxiety and Stress among Govt. nursing college students.

\section{MATERIALS AND METHODS}

A total of 52 students studying in Govt. Nursing College, Akola were included in study based on universal sampling method. A questionnaire-based study was conducted the Depression, Anxiety and Stress Scale (DASS-21).

\section{RESULTS}

Prevalence of depression, anxiety and stress among students was found to be $69.24 \%, 78.85 \%$ and $53.85 \%$ respectively.

\section{CONCLUSION}

Results may help to understand magnitude of problem, forming strategies to help them accordingly and promotion of mental health among students.

\section{KEYWORDS}

Depression, Anxiety, Stress, Nursing, College, Undergraduate, College.

HOW TO CITE THIS ARTICLE: Telgote S, Jadhao A. Depression, anxiety and stress among government nursing college students in Akola: A college-based study. J. Evolution Med. Dent. Sci. 2017;6(90):6297-6300, DOI: 10.14260/jemds/2017/1369

\section{BACKGROUND}

Emotional disorders like depression, anxiety, and stress among communities are important indicators of mental health. Failure to recognise and properly address these issues will lead to increased risk of psychiatric morbidity and undesirable impact on professional life.(1)

There is growing concern over the mental health issues, especially depression and anxiety among adolescent and young adults. Studies around the world have found prevalence of depression, anxiety and stress among adolescent and young adult in the range of 5\%-70\%.(2)

Higher education can be stressful, students have to adapt to a new lifestyle. They have to cope with various stressful situations like staying away from home, academic demands, new social relationships, and uncertainty about future. Students in higher education are vulnerable to mental health problems.(3) Various studies have found high psychological morbidity especially depression and anxiety among university students.(4)(5)(6) Prevalence of depression, anxiety and stress among undergraduates in Malaysia was found to be $29.3 \%, 55.0 \%$, and $21.6 \%$ respectively.

'Financial or Other Competing Interest': None.

Submission 25-10-2017, Peer Review 10-11-2017,

Acceptance 13-11-2017, Published 20-11-2017.

Corresponding Author:

Dr. Amol Jadhao,

Assistant Professor,

Department of Psychiatry,

Government Medical College and Hospital,

Akola.

E-mail: dr.amoljadhao@gmail.com

DOI: $10.14260 /$ jemds $/ 2017 / 1369$

\section{(c) $(1)(5)$}

Medical undergraduates tend to have greater psychological distress than general population.(7) A systemic review reported rates of depression, anxiety and stress among medical students varying from 6.0\%-66.5\%, 7.7\%$65.5 \%$, and $12.2-96.7 \%$ respectively. ${ }^{(8)}$ There is considerable evidence suggesting high prevalence of depression and anxiety among nursing students. As these types of studies are lacking in Indian setting, current study is envisaged.

\section{MATERIALS AND METHODS \\ Design of Study}

Present study is a cross-sectional study of nursing college students studying at Govt. Nursing College, Akola. Study was done during the month of July 2017.

\section{Study Population}

All undergraduate students studying in nursing college were included according to inclusion criteria. A total of 52 students were included in this study after applying inclusion and exclusion criteria.

\section{Inclusion Criteria}

1. Age between $18-25$ years.

2. Students in Govt. Nursing College, Akola.

3. Providing written informed consent.

\section{Exclusion Criteria}

1. Not willing to give written informed consent.

2. Prolonged absentees.

\section{Collection of Sample}

According to inclusion and exclusion criteria, study population was recruited. The nature and purpose of the 
study was explained to study population. A semi-structured proforma was given to study population which aided in collecting sociodemographic details. Self-administered, standardised scale mentioned below was handed over to the sample population.

\section{Sample Size}

After applying inclusion and exclusion criteria, total 52 students were enrolled in study.

\section{Socioeconomic Status}

As per modified B.G. Prasad socioeconomic scale (2017).(9)

\begin{tabular}{|c|c|}
\hline Socioeconomic Class & Per Capita Monthly Income \\
\hline Upper class & $\geq 6254$ \\
\hline Upper middle class & $3127-6253$ \\
\hline Middle class & $1876-3126$ \\
\hline Lower middle class & $938-1875$ \\
\hline Lower class & $<938$ \\
\hline
\end{tabular}

\section{Study Tool}

Depression, Anxiety and Stress Scale (DASS-21)

A self-rating questionnaire, designed to assess severity of depression, anxiety and stress. This instrument has 21 items in three domains. Each domain comprises of seven items assessing three dimensions- depression, anxiety and stress. Based on their experience in the past week, subjects had to rate each item on 4-point rating scale (did not apply to me at all means score 0 , applied to me very much or most of the time means score 3). Then score for depression, anxiety and stress are calculated by adding scores of relevant items. Each subscale is divided into normal, mild, moderate, severe and very severe.

\section{Scoring of DASS-21}

The scale to which each item belongs is indicated by letters $D$ (Depression), A (Anxiety) and S (Stress). For each scale (D, A $\& S)$, sum of the scores noted for identified items. Because the DASS-21 is short form version of DASS-42, the long form version which has 42 items, the final score of each item groups i.e. depression, anxiety and stress needs to be multiplied by two.

\section{Interpreting the DASS-21}

Once multiplied by 2 , each score can now be transferred to DASS profile sheet, enabling comparison to be made between the three scales and also giving percentile rankings and severity labels.

\section{Table 2. DASS-21}

Name: Date:

Please read the statement and circle a number $0,1,2$, or 3 which indicates how much the statement applied to you over the past week. There are no right or wrong answers. Do not spend too much time on any statement.

\section{The Rating Scale is as Follows-}

- $\quad 0$ - Did not apply to me at all- NEVER

- 1- Applied to me to some degree, or some of the timeSOMETIMES

- 2-Applied to me to a considerable degree, or a good part of time- OFTEN

- 3-Applied to me very much, or most of the timeALMOST ALWAYS.

\begin{tabular}{|c|c|c|c|c|c|c|c|c|}
\hline & & $\mathbf{N}$ & $\mathbf{S}$ & $\mathbf{0}$ & AA & D & $\mathbf{A}$ & $\mathbf{S}$ \\
\hline 1 & I found it hard to wind down & 0 & 1 & 2 & 3 & & & \\
\hline 2 & I was aware of dryness in my mouth & 0 & 1 & 2 & 3 & & & \\
\hline 3 & I couldn't seem to experience any positive feeling at all & 0 & 1 & 2 & 3 & & & \\
\hline 4 & $\begin{array}{l}\text { I experienced breathing difficulty (e.g., excessively rapid breathing, } \\
\text { breathlessness in the absence of physical exertion) }\end{array}$ & 0 & 1 & 2 & 3 & & & \\
\hline 5 & I found it difficult to work up the initiative to do things & 0 & 1 & 2 & 3 & & & \\
\hline 6 & I tended to over react to situations & 0 & 1 & 2 & 3 & & & \\
\hline 7 & I experienced trembling (e.g., in the hands) & 0 & 1 & 2 & 3 & & & \\
\hline 8 & I felt that I was using a lot of nervous energy & 0 & 1 & 2 & 3 & & & \\
\hline 9 & $\begin{array}{l}\text { I was worried about situations in which I might panic and make a fool of } \\
\text { myself }\end{array}$ & 0 & 1 & 2 & 3 & & & \\
\hline 10 & I felt that I had nothing to look forward to & 0 & 1 & 2 & 3 & & & \\
\hline 11 & I found myself getting agitated & 0 & 1 & 2 & 3 & & & \\
\hline 12 & I found it difficult to relax & 0 & 1 & 2 & 3 & & & \\
\hline 13 & \begin{tabular}{|l|} 
I felt down-hearted and blue \\
\end{tabular} & 0 & 1 & 2 & 3 & & & \\
\hline 14 & $\begin{array}{l}\text { I was intolerant of anything that kept me from getting me on with what I was } \\
\text { doing }\end{array}$ & 0 & 1 & 2 & 3 & & & \\
\hline 15 & I felt that I was close to panic & 0 & 1 & 2 & 3 & & & \\
\hline 16 & I was unable to become enthusiastic about anything & 0 & 1 & 2 & 3 & & & \\
\hline 17 & I felt that I wasn't worth much as a person & 0 & 1 & 2 & 3 & & & \\
\hline 18 & I felt that I was rather touchy & 0 & 1 & 2 & 3 & & & \\
\hline 19 & $\begin{array}{l}\text { I was aware of actions of my heart in the absence of physical exertion (e.g., } \\
\text { sense of heart rate increases, heart missing a beat) }\end{array}$ & 0 & 1 & 2 & 3 & & & \\
\hline 20 & I felt scared without any good reason & 0 & 1 & 2 & 3 & & & \\
\hline 21 & I felt that life was meaningless & 0 & 1 & 2 & 3 & & & \\
\hline \multicolumn{6}{|c|}{$\begin{array}{cc}\text { Total } \\
\end{array}$} & & & \\
\hline
\end{tabular}




\begin{tabular}{|c|c|c|c|}
\hline Severity & Depression & Anxiety & Stress \\
\hline Normal & $0-9$ & $0-7$ & $0-14$ \\
\hline Mild & $10-13$ & $8-9$ & $15-18$ \\
\hline Moderate & $14-20$ & $10-14$ & $19-25$ \\
\hline Severe & $21-27$ & $15-19$ & $26-33$ \\
\hline $\begin{array}{c}\text { Extremely } \\
\text { severe }\end{array}$ & $\geq 28$ & $\geq 20$ & $\geq 34$ \\
\hline \multicolumn{3}{|l|}{ Table 3. Categorisation of the DASS-21 Scale } \\
\hline
\end{tabular}

\section{Ethical Consideration}

Study approval and written permission was granted by principal of nursing college to protect the rights of the subjects. Study procedure was explained and written information was given to the subjects. Informed written consent from the subjects was taken. Participants who were willing to participate were included in the study. Anonymity of the study subjects and confidentiality was maintained.

\section{RESULTS}

\begin{tabular}{|c|c|c|}
\hline Characteristics & Number (n) & Percentage (\%) \\
\hline \multicolumn{3}{|l|}{$\begin{array}{c}\text { Age Group } \\
\text { (in years) }\end{array}$} \\
\hline $18-19$ & 15 & $28.84 \%$ \\
\hline $20-22$ & 27 & $51.92 \%$ \\
\hline $23+$ & 10 & $19.23 \%$ \\
\hline \multicolumn{3}{|l|}{ Gender } \\
\hline Male & 06 & $11.53 \%$ \\
\hline Female & 46 & $88.46 \%$ \\
\hline \multicolumn{3}{|l|}{ Year } \\
\hline $1^{\text {st }}$ & 19 & $36.53 \%$ \\
\hline $2^{\text {nd }}$ & 17 & $32.69 \%$ \\
\hline $3^{\text {rd }}$ & 16 & $30.76 \%$ \\
\hline \multicolumn{3}{|l|}{ Religion } \\
\hline Hindu & 38 & $73.07 \%$ \\
\hline Buddhist & 12 & $23.07 \%$ \\
\hline Muslim & 2 & $03.84 \%$ \\
\hline \multicolumn{3}{|l|}{ Residence } \\
\hline Urban & 10 & $19.23 \%$ \\
\hline Rural & 42 & $80.76 \%$ \\
\hline \multicolumn{3}{|l|}{ Type of Family } \\
\hline Joint & 19 & $36.53 \%$ \\
\hline Nuclear & 33 & $63.46 \%$ \\
\hline \multicolumn{3}{|l|}{ SES } \\
\hline Upper & 3 & $5.76 \%$ \\
\hline Upper middle & 6 & $11.53 \%$ \\
\hline Middle & 5 & $9.61 \%$ \\
\hline Lower middle & 20 & $38.46 \%$ \\
\hline Lower & 18 & $34.61 \%$ \\
\hline \multicolumn{3}{|c|}{$\begin{array}{c}\text { Table 4. Distribution of Subjects According to } \\
\text { Sociodemographic Characteristics }\end{array}$} \\
\hline
\end{tabular}

Age of students participated was in the range of 18 years to 25 years, majority (51.92\%) of them were in the range of 20-23 years. Majority of students were females (88.46\%), studying in first year (36.53\%), Hindus $(73.07 \%)$, from rural area $(80.76 \%)$, living in nuclear families $(63.46 \%)$, from lower middle class (38.46\%).

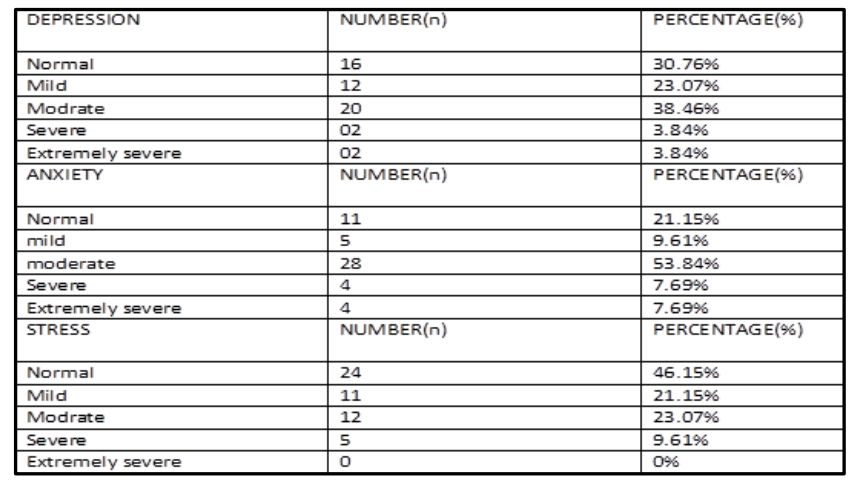

Table 5. Distribution of Study Population as per Severity of Depression, Anxiety and Stress

Out of 52 students, 36 (69.24\%) suffered from depression, majority (38.46) had moderate depression. Prevalence of anxiety was found to be $78.85 \%$, majority (53.84\%) had moderate anxiety. Prevalence was stress was found to be $53.85 \%$, majority (23.07\%) had moderate stress.

\section{DISCUSSION}

Prevalence of depression in our study was found to be 69.24\%. Similar study from West Bengal by Chatterjee et al $(2014)^{(10)}$ found $63.9 \%$ prevalence of depression among nursing students.

In our study, anxiety among students was found to be $78.85 \%$, which was higher than the nursing college student in Greece (71.8\%).(11) A study by Iqbal et al (2015) among medical undergraduate students in India also found lower prevalence of anxiety (66.9\%)(12) compared to current study.

Prevalence of stress in our study was $53.85 \%$, which is in line with Iqbal et al(53\%).(12) A study by Eva E et al (2015)(13) among medical undergraduates from our neighbouring country Bangladesh have found overall 54\% prevalence of stress among students.

\section{CONCLUSION}

Thus, we conclude that the prevalence of depression, anxiety and stress was high among nursing students. It may help educators to understand the difficulties of students, and help them accordingly. High prevalence of psychiatric morbidity warrants formation of strategies for early identification and intervention, and overall promotion of mental health among students.

\section{Limitations}

The present study was institution-based cross-sectional study. Due to small sample size, it lacks representativeness and results of the study cannot be generalised. Another limitation is that the study was based on results from selfadministered questionnaire, hence reporting bias cannot be totally eliminated.

\section{ACKNOWLEDGEMENT}

We wish to extend our sincere gratitude to all students who participated in the study. We thank college authorities for their support and cooperation. 


\section{REFERENCES}

[1] Al-Naggar RA, Al-Naggar DH. Prevalence and associated factors of emotional disorder among Malaysian university students. International Journal of Collaborative Research on Internal Medicine \& Public Health 2012;4(7):1401-11.

[2] Sahoo S, Khess CR. Prevalence of depression, anxiety, and stress among young male adults in India: a dimensional and categorical diagnoses-based study. J Nerv Ment Dis 2010;198(12):901-4.

[3] Manthorpe NSJ. Responding to students' mental health needs: impermeable systems and diverse users. J Ment Heal 2001;10(1):41-52.

[4] Wong JG, Cheung EP, Chan KK, et al. Web-based survey of depression, anxiety and stress in first-year tertiary education students in Hong Kong. Aust New Zeal J Psychiatry 2006;40(9):777-82.

[5] Adewuya AO, Ola BA, Aloba 00, et al. Depression amongst Nigerian university students. Prevalence and sociodemographic correlates. Soc Psychiatry Psychiatr Epidemiol 2006;41(8):674-8.

[6] Nerdrum P, Rustøen T, Rønnestad MH. Student psychological distress: a psychometric study of 1750 Norwegian 1st-year undergraduate students. Scand J Educ Res 2006;50(1):95-109.
[7] Dyrbye LN, Thomas MR, Shanafelt TD. Systematic review of depression, anxiety, and other indicators of psychological distress among U.S. and Canadian medical students. Acad Med 2006;81(4):354-73.

[8] Hope V, Henderson M. Medical student depression, anxiety and distress outside North America: a systematic review. Med Educ 2014;48(10):963-79.

[9] Singh T, Sharma S, Nagesh S. Socio-economic status scales updated for 2017. International Journal of Research in Medical Sciences 2017;5(7):3264-7.

[10] Chatterjee S, Saha I, Mukhopadhyay S, et al. Depression among nursing students in an Indian government college. Br J Nurs 2014;23(6):316-20.

[11] Papazisis G, Vlasiadis I, Papanikolaou N, et al. Depression and anxiety among nursing students in Greece. Ann Gen Psychiatry 2008;7(Suppl 1):S209.

[12] Iqbal S, Gupta S, Venkatarao E. Stress, anxiety and depression among medical undergraduate students and their socio-demographic correlates. Indian J Med Res 2015;141(3):354-7.

[13] Eva EO, Islam MZ, Mosaddek ASM, et al. Prevalence of stress among medical students: a comparative study between public and private medical schools in Bangladesh. BMC Res Notes 2015;8:327. 